\title{
O comportamento exploratório de bebês e o comportamento de mães com indicadores de depressão no contexto da psicoterapia breve mãe-bebê: um olhar objetivo e subjetivo
}

\author{
Cristiane Alfaya \\ Universidade Federal do Recôncavo da Bahia \\ Rita Sobreira Lopes \\ Luís Carlos Prado \\ Universidade Federal do Rio Grande do Sul
}

\begin{abstract}
RESUMO
O presente estudo examinou o comportamento exploratório dos bebês, e o comportamento das mães com indicadores de depressão, frente ao comportamento exploratório dos bebês, durante a psicoterapia breve mãe-bebê, no primeiro ano de vida dos bebês. Foram considerados os aspectos objetivos e subjetivos da interação, envolvidos no comportamento exploratório do bebê. Para tanto, foram realizados três estudos de casos atendidos em sessões de psicoterapia. O comportamento exploratório foi descrito e analisado conforme as categorias manipulação exploratória fina e ampla, e de locomoção exploratória em direção ao ambiente e ao brinquedo. O comportamento materno foi descrito e analisado conforme as categorias direto e indireto, construídas a partir da descrição da observação. Apoiando-se na teoria de separação-individuação, os resultados mostraram que os bebês apresentaram comportamentos de manipulação exploratória fina, ampla, locomoção exploratória em direção ao ambiente, e aos brinquedos, o que indica desenvolvimento da autonomia na perspectiva do desenvolvimento emocional. Do ponto de vista das mães, os resultados apóiam as evidências de que a mãe, ao interagir com o bebê, relaciona-se não apenas com o comportamento observado de maneira objetiva, mas também com imagens (modelos), os quais pertencem à mãe e aparecem na interação com o bebê por meio da identificação projetiva.
\end{abstract}

Palavras-chave: comportamento exploratório do bebê; psicoterapia mãe-bebê; depressão materna

\section{ABSTRACT \\ Infant's exploratory behavior and the behavior of mothers with depression indicators in the context of brief mother-infant psychotherapy: an objective and subjective view}

The present study aimed to examine infant's exploratory behaviour, as well as the behaviour of mothers with indicators of depression during a brief mother-infant psycotherapeutic process, in the first year of the infant's life. Both objective and subjective aspects of interaction involved in infant exploratory behaviour were taken into consideration. Three case studies of dyads seen in motherinfant psychotherapy sessions were carried out. The infant's exploratory behavior was described and analyzed according to categories fine and ample exploratory manipulation, as well as of exploratory locomotion towards the environment and toys. Mothers' behaviors regarding infants' exploratory behavior was also described and analyzed according to categories direct and indirect behavior, constructed based on the observation description material. Based on the separation-individuation theory, the results showed that infants of mothers with depression presented exploratory behaviors such as fine and ample exploratory manipulation, exploratory locomotion towards the environment and toys, which indicate emotional autonomy development. From the mothers' point of view, the results give support to the evidence that when the mother interacts with the baby she not only relates to the observed, objective behavior but also to images (models) which belong to the mother and appear in the interaction with the infant through projective identification.

Keywords: infant's exploratory behavior; mother-infant psychotherapy; maternal depression 
O interesse por compreender o comportamento exploratório dos bebês, e o comportamento das mães com indicadores de depressão frente ao comportamento exploratório dos bebês, surgiu a partir da literatura sobre o desenvolvimento infantil no contexto da depressão materna (Field, 1997a; Field, 1997b; Field \& cols., 1996; Field, Healy, Goldstein \& Guthertz, 1990; Murray, Fiori-Cowley \& Hooper, 1996; Whiffen \& Gotlib, 1989), a qual não contemplava a preocupação em compreender a interação mãe-bebê sob o ponto de vista subjetivo, considerando a história de vida das mães. A maioria dos estudos empíricos encontrados nesta área utiliza uma metodologia quantitativa e comparativa, afirmado a existência de diferenças na qualidade dos comportamentos interativos na díade mãe-bebê, assim como no comportamento exploratório do bebê de mães com e sem indicadores de depressão no primeiro ano de vida do bebê.

Em termos do comportamento interativo das mães nas situações de interação face-a-face e jogo livre, os estudos mostram que as mães com indicadores de depressão interagem com seus bebês de maneira bastante peculiar, sendo, na maioria das vezes, caracterizada por comportamentos de intrusividade ou de retraimento (Cummings \& Davies, 1994; Field, 2000; Hart, Field \& Del Valle, 1998), assim como uma baixa sensibilidade (Cummings \& Davies, 1994; Murray e cols., 1996; Murray, Hipwell \& Hooper, 1996), olham menos para seus bebês, tocam menos e conversam menos com os bebês (Cohn, Campbell, Matias \& Hopkins, 1990) em comparação com as mães sem indicadores de depressão.

No tocante ao comportamento exploratório dos bebês de mães com inidicadores de depressão, os poucos estudos encontrados indicam prejuízo no desenvolvimento dos bebês, que aos 12 meses de vida apresentam um comportamento exploratório mais limitado na situação de jogo livre, se envolvendo menos nas tarefas de exploração, levando mais tempo para olhar os brinquedos, manipulando menos, e alcançando menos os brinquedos, evitando mais, assim como demonstram menos expressões de afeto positivo e um maior número de expressões de afeto negativo (Field \& cols., 1996; Hart \& cols., 1998; Hart, Jones, Field \& Lundy, 1999) em comparação aos bebês de mães sem indicadores de depressão.

Neste sentido, os estudos estabelecem uma relação direta entre os comportamentos maternos e o comportamento exploratório dos bebês, bem como tendem a enfatizar os prejuízos no comportamento explorató- rio dos bebês de mães com mães com indicadores de depressão, sem procurar compreender os aspectos subjetivos envolvidos na interação mãe-bebê durante o comportamento exploratório. O presente estudo considera tanto os apectos objetivos, como os aspectos subjetivos envolvidos na interação mãe-bebê, observados no contexto clínico de psicoterapia, através da identificação projetiva.

\section{0 comportamento exploratório do bebê e o papel da mãe}

De acordo com Mahler, Pine e Bergman (1975/ 2002), por volta do quarto ou quinto mês de vida do bebê os fenômenos comportamentais como o sorriso específico e preferencial dirigido à mãe, parece indicar o início da primeira subfase de diferenciação do processo de separação-individuação. Segundo os autores, nesta subfase, a criança apresenta-se mais permanentemente alerta sempre que está acordada, demonstrando persistência e direcionamento de objetivos, o que foi chamado de manifestação comportamental de desabrochamento. Em torno do sexto mês, o bebê inicia uma experiência de tentativa de separaçãoindividuação, que pode ser observada pelos comportamentos exploratórios da criança de puxar o cabelo, orelhas e o nariz da mãe, pôr comida em sua boca e afastar o corpo dela de maneira a poder olhá-la melhor, examinando-a e ao mundo ao seu redor. Entre o sexto e o sétimo mês de vida do bebê há o auge da exploração manual, tátil e visual do rosto da mãe, assim como das partes cobertas (vestidas) e descobertas do corpo desta, e já pode haver um envolvimento em jogos de esconde-esconde. Nesse período, aparece o padrão visual do bebê de confrontar com a mãe, iniciando a exploração comparativa, passando a se interessar pela mãe, comparando-a com o outro.

De acordo com a teoria de separação-individuação (Mahler \& cols., 1975/2002), o período de treinamento, o qual é dividido em inicial e propriamente dito, se sobrepõe à subfase de diferenciação. $\mathrm{O}$ treinamento inicial é caracterizado pela habilidade da criança de se afastar fisicamente da mãe, seja engatinhando, cambaleando ou ficando de pé, sem desligarse dela. Já no período de treinamento propriamente dito, a criança pode se locomover livre e diretamente. Com isso, o interesse da criança se amplia para os objetos inanimados como para a fralda, o brinquedo, a mamadeira, explorando esses objetos visualmente, experimentando o seu gosto, textura, e cheiro através dos órgãos perceptivos de contato, particularmente as mãos e a boca. A expansão da capacidade locomotora, 
durante a fase de treinamento, possibilita que a criança assuma um papel mais ativo na determinação da proximidade e distanciamento da mãe, assim como da exploração do ambiente, pois há mais coisas para ver, ouvir e tocar.

$\mathrm{Na}$ subfase de treinamento propriamente dito, que ocorre por volta do dez aos dezoito meses, o mundo se torna a paixão do bebê. $\mathrm{O}$ bebê parece encantado com as suas próprias competências e seu mundo. Os primeiros passos independentes da criança em posição vertical marcam o início do período de treinamento por excelência. É o auge do narcisismo infantil, já que há um grande investimento da criança em suas próprias funções, em seu próprio corpo e nos objetos e objetivos de sua realidade. A criança se concentra no exercício e domínio de suas próprias habilidades e capacidades autônomas independente do outro ou da mãe. Em termos do desenvolvimento emocional, o ato de andar proporciona à criança um aumento acentuado de sua descoberta da realidade e do ato de testá-lo sob seu próprio controle e domínio. O andar possui um grande significado tanto para a mãe, como para a criança, pois a criança que começa a andar com a aquisição da locomoção independente em posição vertical, mostra a competência para entrar no mundo dos seres humanos independentes. A expectativa e a confiança que a mãe demonstra quando sente que seu filho é capaz de ter êxito, parece ser um importante agente do sentido de segurança da criança e também o encorajamento inicial para que ela transforme uma parte de sua onipotência em prazer ligado a sua própria autonomia e a sua auto-estima em desenvolvimento (Mahler \& cols., 1975/2002). Cassidy e Berlin (1994) lembram que os pais, quando se sentem ameaçados com a expansão dos comportamentos exploratórios do bebê, podem falhar em responder às necessidades de apego no início da exploração da criança, a fim de satisfazer a sua necessidade de dependência. Sendo assim, os pais não encorajam o desenvolvimento das competências do bebê em direção à autonomia no período de treinamento, manifestando comportamentos de retraimento, ou punindo a criança quando esta demonstra comportamentos de exploração.

Mais recentemente, e na tentativa de compreender a relação entre os aspectos interativos da díade mãebebê e o desenvolvimento sócio-emocional da criança Brazelton e Cramer (1992) destacam o sentimento de empatia nas mães. Para o desenvolvimento do controle homeostático, é fundamental que o bebê tenha adquirido o controle dos sistemas de entrada e saída das informações, sendo capaz de permitir ou não a recepção de estímulos, além de controlar seus próprios sistemas fisiológicos e estados de consciência (sono profundo, sono ativo, sonolência, alerta acordado, alerta irrequieto, e choro). Para tanto, o sentimento de empatia nas mães é fundamental, pois as coloca em contato com os sistemas de controle de seus bebês, auxi-liando a criança a se auto-regular nos períodos de desorganização. Esse pressuposto lembra a concepção de Winnicott (1956/1982) a respeito da preocupação materna primária, a qual é definida como uma condição que se desenvolve gradualmente e se torna um estado de sensibilidade aumentada durante a gravidez, continuando após o parto. A mãe que desenvolve o estado de preocupação materna primária fornece um ambiente, no qual a constituição do bebê pode se mostrar, suas tendências de desenvolvimento podem começar a se revelar, o bebê pode experimentar um movimento espontâneo e dominar as sensações na fase inicial da vida (Winnicott, 1960/1983). O autor também sugere que é a partir da matriz de uma relação mãe-bebê suficientemente boa que o ego infantil será capaz de se desenvolver, tornando-se uma unidade, com o objetivo principal de se desenvolver, rumo à independência. Nesse sentido, o desenvolvimento do comportamento exploratório do bebê em direção a sua independência deve ser apreendido no contexto das relações com pessoas significativas.

Além do sentimento de empatia, Brazelton e Cramer (1992) salientam os comportamento maternos de permissividade e encorajamento, para o surgimento da autonomia, que começa a se desenvolver por volta dos quatro meses de vida do bebê. Quando a mãe é capaz de permitir ou mesmo encorajar o bebê em seus comportamentos, ela está promovendo o desenvolvimento do comportamento exploratório da criança. $\mathrm{O}$ controle da criança sobre a atenção dos pais permite que ela comece a se separar e a se tornar independente. A constatação, por parte do bebê, de seu próprio poder de controle, conduz à exploração do ambiente, a qual foi promovida pela capacidade materna de entrar em sintonia com o bebê. Bebês de cinco meses de idade começam a dominar o comportamento da mãe por meio de sua capacidade de iniciar e interromper a interação.

Além destes aspectos objetivos, observados através dos comportamentos interativos, Brazelton e Cramer (1992) também consideram a presença de aspectos subjetivos, os quais estão envolvidos na interação, o que os autores denominam como interações imaginárias. Eles afirmam que a mãe ao interagir com o bebê se relaciona não apenas com as características inatas 
do bebê como o comportamento observado de maneira objetiva, mas se relaciona também com os aspectos subjetivos a partir de seus valores e história de vida, a qual aparece na interação através do significado subjetivo atribuído ao bebê e à relação com o bebê. Este significado subjetivo atribuído ao bebê ocorre por meio da identificação projetiva da mãe às características do bebê, sendo este um elemento essencial para o desenvolvimento emocional do bebê. Sendo assim, ao falar do comportamento exploratório do bebê é preciso considerar os processos interativos de caráter objetivo e subjetivo na díade mãe-bebê.

\section{Depressão materna}

A depressão relacionada ao nascimento de um bebê refere-se a um conjunto de sintomas que iniciam geralmente entre a quarta e a oitava semana após o parto e podem persistir por até um ano, atingindo de 10 a $15 \%$ das mulheres (Cooper, Campbell, Day, Kennerley \& Bond, 1988; Cooper \& Murray, 1997; Kumar \& Robson, 1984; O’Hara, Zekoski, Philipps \& Wright, 1990). Esses sintomas incluem irritabilidade, choro freqüente, sentimentos de desamparo e desesperança, falta de energia e motivação, desinteresse sexual, transtornos alimentares e do sono, a sensação de ser incapaz de lidar com novas situações, bem como queixas psicossomáticas (Klaus, Kennell \& Klaus, 2000; Shermann \& Alfaya, 2000).

De acordo com a literatura, diversos fatores estão relacionados à etiologia da depressão materna (Cooper \& Murray, 1997). Reading e Reynolds (2001) classificaram os fatores de risco para a depressão materna em três categorias: a primeira refere-se à qualidade dos relacionamentos interpessoais da nova mãe, particularmente com o seu parceiro. A segunda categoria relaciona-se à gravidez e ao parto e à ocorrência de eventos de vida estressantes. A terceira categoria refere-se à relação existente entre a presença de depressão e adversidades sócio-econômicas. Entre os fatores mais destacados nos estudos, salienta-se a associação entre a ocorrência da depressão materna e o baixo apoio oferecido pelo parceiro ou por outras pessoas com quem a mãe mantém relacionamento (Beck, 2002; Beck, Reynolds \& Rutowsky, 1992; Brown, Andrews, Harris, Adler \& Bridge, 1986; Deal \& Holt, 1998; Pfost, Stevens \& Lum, 1990; Romito, SaurelCubizolles \& Lelong, 1999). Outros fatores também tem sido mencionados, em particular a falta de planejamento da gestação, nascimento prematuro e morte do bebê (Kumar \& Robson, 1984), dificuldade em amamentar (Warner, Appleby, Whitton \& Faragher,
1996), dificuldades no parto, problemas de saúde da criança (Romito \& cols., 1999) e dificuldades relacionadas ao retorno ao trabalho (Hock \& DeMeis, 1990).

Cramer e Palácio-Espasa (1993) defendem que as vicissitudes da interação mãe-bebê podem estar mais associadas à ocorrência da depressão materna após o nascimento da criança do que a uma patologia preexistente da mãe. De acordo com estes autores a depressão materna é entendida com uma das possíveis manifestações de dificuldade de adaptação na transição para a maternidade, tendo em vista o luto desenvolvimental em que a mulher precisa abdicar o papel exclusivo de filha e assumir o papel de mãe, revivendo a experiência da relação mãe-filha. Por vezes, a relação mãe-filha pode estar permeada por situações de conflito vividas e que com a maternidade são atualizadas na relação com o bebê. Sendo assim, a depressão materna é considerada como a manifestação de dificuldades para lidar com a nova condição. Dificuldades, estas, relacionadas à história de vida da mulher, considerando os aspectos subjetivos de seus relacionamentos com pessoas significativas, as quais aparecem através de sintomas como indicadores de depressão.

\section{Psicoterapia breve mãe-bebê $\hat{e}^{1}$}

O início da psicoterapia breve como uma técnica propriamente dita se deu, de acordo com Braier (1997), através do trabalho de Alexander e French, na década de 40. Além de caracterizar os princípios técnicos desta abordagem - como flexibilidade do terapeuta, estabelecimento de objetivos e planejamento do tratamento - cunharam o conceito de experiência emocional corretiva. Este conceito enfatiza o momento atual e a relação terapêutica, ao invés da rememoração de experiências do passado.

A psicoterapia breve mãe-bebê, realizada no presente estudo, busca a conexão entre os elementos do passado da mãe, considerando a sua história de vida, e os do presente com o bebê, através da capacidade de insight da mãe, e da postura empática do clínico. Nesta abordagem, o clínico deve privilegiar a observação da natureza das solicitações recíprocas e as reações a elas na díade mãe-bebê, através de modalidades interativas tais como o tom da voz, o olhar, o tato, assim como os gestos, que virão acompanhados de uma determinada intensidade, freqüência, contingência ou anticontingência, observando, ainda, se a reação a uma solicitação produz recepção ou evitação, aprovação ou rejeição no outro (Cramer \& PalacioEspasa, 1993).

Interação em Psicologia, Curitiba, jul./dez. 2006, (10)2, p. 321-332 
De acordo com Cramer e Palacio-Espasa (1993), o tratamento psicoterápico conjunto de pais e bebê pode trazer uma melhora significativa nos sintomas no bebê, nos comportamentos interativos e nas representações dos pais acerca da parentalidade, sendo que este tratamento ocorre em três níveis: 1) determinação da natureza do sintoma e do confronto da mãe com o seu próprio conflito e a respeito do problema que é transferido ao bebê; 2) estabelecimento de uma conexão entre as falhas interacionais observadas durante a sessão e a correspondência mental do conflito na mãe; 3) estabelecimento de ligações entre o conflito presente da díade com os conflitos do passado da mãe. Para tanto, os autores consideraram fundamental o desenvolvimento e a manutenção da aliança terapêutica, bem como a empatia.

Outro aspecto referente à técnica da psicoterapia mãe-bebê proposta por Cramer e Palácio-Espasa (1993) refere-se à atenção do terapeuta, a qual deve ser igualmente dividida entre a observação das interações da díade mãe-bebê ou tríade pai-mãe-bebê e a escuta dos pais. O clínico irá privilegiar a observação da natureza das solicitações recíprocas e as reações a elas, através de modalidades interativas, tais como: vocalizações, troca de olhares, toques e gestos. Os autores consideraram que são principalmente as interrupções das trocas comunicativas, as evitações e as proibições que irão revelar a ativação de defesas no nível comportamental, o que permitirá ao clínico observar os conflitos subjacentes. A partir disso, o terapeuta poderá tecer interpretações para os pais a respeito de suas defesas intrapsíquicas. Isso ocorre quando há uma coincidência entre um enunciado de uma fantasia conflitiva e a atualização da defesa relacionada no nível de uma evitação, proibição, ruptura de contato, ou seja: um sintoma interativo observado, o que os autores chamaram de sequiência interativa sintomática. Esta seqüência é o equivalente interagido (e interpessoal) de um conflito intrapsíquico.

A brevidade do tratamento é possível em decorrência da velocidade das modificações subjetivas, interativas e sintomáticas, da mobilização psíquica da mãe (capacidade de estabelecer vínculos, revivência da neurose infantil, insight, mobilização dos afetos), e da própria constelação psicodinâmica do pós-parto, que abrange os primeiros anos de vida do bebê (Cramer \& Palácio-Espasa, 1993).

A psicoterapia breve mãe-bebê é indicada nos casos de distúrbios funcionais do bebê, angústias de separação, distúrbios de apego mãe-bebê (Cramer \& Palácio-Espasa, 1993; Prado, 1996; Stern, 1997).
Também podem ser obtidos bons resultados clínicos com mães apresentando um escore de depressão superior a 17, conforme avaliado pelo Inventário Beck de Depressão (BDI - Beck \& Steer, 1993), quando se tratarem de depressões desencadeadas pela transição para a maternidade, e não de estruturas depressivas de base (Cramer \& Palácio-Espasa, 1993).

\section{Objetivos e questões do estudo}

O presente estudo buscou compreender o comportamento exploratório dos bebês, e os comportamentos das mães com indicadores de depressão frente aos comportamentos dos bebês, no contexto da psicoterapia. Para tanto, foram levantadas duas questões de pesquisa, a saber: Como se caracteriza o comportamento exploratório dos bebês de mães com indicadores de depressão no contexto da psicoterapia? E como se caracteriza o comportamento das mães com indicadores de depressão frente ao comportamento exploratório dos bebês no contexto da psicoterapia?

\section{MÉTODO}

\section{Participantes}

A seguir, apresentam-se as participantes do estudo, conforme mostra a Tabela 1.

Conforme a Tabela 1, participaram deste estudo três bebês nascidos a termo e a suas mães. Os bebês tinham entre 8 e 10 meses de vida, não apresentavam problemas de saúde neonatal e tinham um desenvolvimento esperado para a sua faixa etária, de acordo com a avaliação das Escalas Bayley do Desenvolvimento Infantil - BSDI-II (Bayley, 1993). As mães tinham entre 26 e 33 anos de idade, e ensino médio completo. Como critério para a participação no estudo, as mães apresentavam indicadores de depressão (escore igual ou acima de 12 pontos) de acordo com o Inventário Beck de Depressão - BDI (Beck \& Steer, 1993), confirmados por uma Entrevista Diagnóstica (GIDEP/NUDIF, 2003). Todas residiam em Porto Alegre, sendo de nível sócio-econômico médio e médio-baixo. Nem todas moravam com o pai do bebê. As famílias faziam parte do estudo longitudinal "O impacto da psicoterapia para a depressão materna e para a interação pais-bebê: Estudo longitudinal do nascimento ao segundo ano de vida do bebê $\hat{e}^{2}$ (Piccinini, 2003), realizado pelo Núcleo de Infância e Família NUDIF, integrante do Grupo de Interação Social, Desenvolvimento e Psicopatologia - GIDEP/CNPq. Os casos estudados foram supervisionados por um profissional experiente na área clínica. 
Tabela 1. Participantes

\begin{tabular}{|c|c|c|c|c|c|c|c|c|}
\hline Casos & Idade mãe & Idade bebê & BSDI (II) bebê & Sintomas mãe & BDI mãe & Situação conjugal & Escolaridade & Ocupação \\
\hline Casol & 26 anos & 10 meses & $\begin{array}{l}\text { Esperado para a } \\
\text { idade }\end{array}$ & $\begin{array}{l}\text { Irritação, } \\
\text { Ansiedade, } \\
\text { Solidão, } \\
\text { Sobrecarga }\end{array}$ & leve 12 pontos & estável & Ensino médio & desempregada \\
\hline Caso II & 33 anos & 8 meses & $\begin{array}{l}\text { Esperado para a } \\
\text { idade }\end{array}$ & $\begin{array}{l}\text { Irritação, } \\
\text { Angústia, } \\
\text { Insônia, } \\
\text { Tristeza, Culpa }\end{array}$ & $\begin{array}{l}\text { moderado } 24 \\
\text { pontos }\end{array}$ & solteira & Ensino médio & $\begin{array}{l}\text { auxiliar adminis- } \\
\text { trativa }\end{array}$ \\
\hline Caso III & 31 anos & 10 meses & $\begin{array}{l}\text { Esperado para a } \\
\text { idade }\end{array}$ & $\begin{array}{l}\text { Medo, } \\
\text { Choro }\end{array}$ & leve 12 pontos & solteira & Ensino médio & desempregada \\
\hline
\end{tabular}

O Caso I foi encaminhado pelo Serviço de Psicologia do Hospital de Clínicas de Porto Alegre por suspeita de depressão. A mãe relatou estar se sentindo irritada e que a sua vida não era mais a mesma desde o nascimento do bebê, que ocorreu por descuido. O seu relacionamento com o marido também não estava bem, pois brigavam muito. Foi criada pela irmã da senhora que adotou a sua mãe, a qual chamava de avó, desde os seus dois anos e meio de idade. Sentia-se abandonada pelos seus pais.

O Caso II procurou atendimento por intermédio de anúncio no jornal, por achar que estava deprimida. Ainda por telefone, ela se fez por conhecer como mãe solteira. A mãe relatou ter dificuldades para dormir desde o nascimento do bebê, percebendo-se mais irritada e chateada com o fato de não poder sair à noite como costumava fazer até o nascimento da filha. Desde o final da gravidez, ela foi morar na casa de seus pais. Contou que sempre se sentiu próxima de sua mãe e distante de seu pai. Também se sentia culpada com a ausência do pai do bebê.

O Caso III, também procurou atendimento por intermédio de anúncio no jornal, por achar que estava deprimida. A mãe, que também era solteira, relatou estar sentindo medo por não conseguir cuidar do bebê, sozinha. Contou que desde a gravidez chorava muito. Desde o início da gravidez ela foi morar na casa de sua irmã. Contou que sempre se sentiu muito próxima de seus pais. Também se sentia culpada com a ausência do pai do bebê.

\section{Delineamento e procedimentos}

Neste estudo foi utilizado um delineamento de Estudo de Caso Coletivo (Stake, 1994), de caráter longitudinal, buscando-se compreender o comportamento exploratório dos bebês, e os comportamentos de mães com indicadores de depressão, frente ao comportamento exploratório dos bebês no contexto da psicoterapia, a partir de uma abordagem qualitativa.

Todos os procedimentos foram realizados no Laboratório de Observação do Instituto de Psicologia da Universidade Federal do Rio Grande do Sul, para que fossem gravados em áudio e vídeo, mediante Consentimento Livre e Esclarecido. Na seqüência, aplicavase o Inventário de Depressão de Beck - BDI (Beck \& Steer, 1993), e a Entrevista Diagnóstica (GIDEP/ NUDIF, 2003), para se investigar os indicadores de depressão materna. A partir desta avaliação, os casos eram encaminhados para a psicoterapia. No presente estudo, os casos realizaram entre 8 e 12 sessões. Todos os casos tiveram variações de duração de tempo em cada sessão, mas ocorria em torno de uma hora. Caso houvesse necessidade, após o período de atendimento oferecido gratuitamente, as participantes eram encaminhadas para atendimento oferecido pela Clínica de Atendimento Psicológico da UFRGS.

\section{Considerações éticas}

O projeto longitudinal, do qual o presente estudo faz parte, foi aprovado por diversos comitês de ética (Hospital de Clínicas de Porto Alegre: n ${ }^{\circ}$ 03-068 de 14.02.2003; Hospital Materno Infantil Presidente Vargas: $n^{\circ}$ 05-03 de 02.04.2003; e Universidade Federal do Rio Grande do Sul: no 200396 de 15.05.2003), tendo sido considerado adequado e metodologicamente de acordo com a resolução 196/96 de Conselho Nacional de Saúde.

\section{Procedimentos de análise dos resultados}

A fim de se caracterizar o comportamento exploratório dos bebês, foram elaboradas quatro categorias a priori: 1. Manipulação exploratória fina; 2. Manipulação exploratória ampla; 3. Locomoção exploratória em direção ao ambiente; 4. Locomoção explorató- 
ria do brinquedo. As categorias do comportamento materno foram elaboradas após a descrição dos comportamentos das mães frente aos comportamentos exploratórios dos bebês:

1. Comportamento Direto: olha para o bebê; olha e pega brinquedos e objetos; olha e sorri; olha e verbali$\mathrm{za}$, e 2. Indireto: aproxima os brinquedos do bebê sem olhar; deixa o bebê pegar brinquedos e objetos de sua mão sem olhar; retira brinquedos e objetos do bebê sem olhar; pega brinquedos e objetos entregues pelo bebê sem olhar; apóia o bebê fisicamente sem olhar. A categorização dos comportamentos dos bebês e das mães foi realizada por dois observadores, a fim de se ter um consenso. A partir da descrição geral da sessão, realizou-se a compreensão dinâmica de cada sessão com base na interpretação, considerando a história de vida das mães através das falas e seus comportamentos, especialmente, aqueles frente aos comportamentos de exploração dos bebês.

\section{Instrumentos e materiais}

O Inventário Beck de Depressão - BDI (Beck \& Steer, 1993) e uma Entrevista Diagnóstica (GIDEP/ NUDIF, 2003) foram utilizadas para se avaliar a depressão. O BDI é a escala auto-avaliação da depressão mais amplamente usada tanto em pesquisa como em clínica. A Entrevista Diagnóstica envolve questões sobre sono; apetite; sentimentos de tristeza, culpa, cansaço, preocupação, ansiedade; auto-estima; ideação suicida; uso de medicações; problemas emocionais na família.

\section{RESULTADOS E DISCUSSÃO}

A seguir, apresenta-se, resumidamente, na Tabela 2, os resultados gerais do presente estudo. Em seguida, são discutidos os resultados a partir dos eixos: Comportamento exploratório do bebê, e Comportamentos maternos.

Tabela 2. Resultados Gerais

\begin{tabular}{|c|c|c|c|}
\hline Casos & Comportamento exploratório do bebê & Comportamento materno & Identificação projetiva \\
\hline \multirow[t]{2}{*}{ Casol } & $\begin{array}{l}\text { Manipulação fina e ampla; Locomoção ambiente e } \\
\text { brinquedo }\end{array}$ & Indireto / Direto $\mathrm{A} /$ Indireto $\mathrm{B} /$ Direto $^{\mathrm{C}}$ & $\begin{array}{l}\text { - Distante de seus afetos ao falar de si } \\
\text { e do bebê. }\end{array}$ \\
\hline & & & - Rejeição, abandono (pais). \\
\hline Caso II & $\begin{array}{l}\text { Manipulação fina e ampla; Locomoção ambiente e } \\
\text { brinquedo }\end{array}$ & Direto & $\begin{array}{l}\text {-Proximidade (mãe). } \\
\text { - Mãe compensando a falta do pai. }\end{array}$ \\
\hline \multirow[t]{2}{*}{ Caso III } & Manipulação fina e ampla; Locomoção ambiente ${ }^{\mathrm{D}} \mathrm{e}$ & Direto - limita espaço exploração / & - Insegurança, medo. \\
\hline & brinquedo $\mathrm{E}$ & Direto - amplia espaço exploração $F$ & $\begin{array}{l}\text { - Superproteção, dependência (pais e } \\
\text { familiares). }\end{array}$ \\
\hline
\end{tabular}

A - na 4, 5 e 6 sessão; B - na 7 sessão; C - a partir 10 sessão até o final.

$D$ - a partir da 4 sessão até o final; $E$ - a partir da 6 sessão até 0 final; $F$ - a partir da 4 sessão até 0 final

\section{Comportamento exploratório do bebê}

De acordo com os resultados apresentados na Tabela 2, foram observados comportamentos de manipulação exploratória fina, como pegar, apertar, levar à boca brinquedos e objetos, bem como comportamentos de manipulação exploratória ampla, como erguer, balançar, bater, jogar e chutar brinquedos e objetos, em cada sessão de psicoterapia. Do ponto de vista do desenvolvimento emocional, na teoria do processo de separação-individuação (Mahler \& cols., 1975/2002), estes comportamentos de manipulação exploratória são considerados como de desabrochamento, caracterizando a subfase de diferenciação.

A descrição do comportamento exploratório do bebê também permitiu a observação de outros comportamentos de desabrochamento, da subfase de diferenciação, como as demonstrações de direcionamento de objetivos e persistência. Estes comportamentos foram observados nos bebês quando, diante de vários brinquedos, pegavam e balançavam com mais freqüência alguns brinquedos ou objetos em detrimento de outros. Também, quando as mães aproximavam mais de um brinquedo dos bebês e estes olhavam e pegavam um específico. Por vezes, ocorria de os bebês pegarem um outro brinquedo, que não o oferecido pelas mães. Estes comportamentos também poderiam estar indicando a presença de preferências. Para Turnbull e Turnbull (2003), apesar de o bebê não ter a definição clara de seus valores, já apresenta preferência em relação àquilo que traz conforto, prazer e segurança, regulando os seus próprios comportamentos. $\mathrm{Na}$ medida em que a criança faz escolhas e indica preferências quando explora o ambiente, está construindo o sentido de mundo que a cerca, o que gera sentimentos de competência e confiança. Com isso, a 
criança é capaz de ampliar a exploração do ambiente, através dos comportamentos de manipulação e de locomoção.

Nos bebês de mães com indicadores de depressão também foram observados comportamentos de locomoção exploratória em direção ao ambiente (cadeira, paredes, porta, colchão, bolsa, cadeirinha, entre outros), através do engatinhar, caminhar segurando-se nos móveis e de caminhar livremente. Da mesma forma, observou-se comportamentos de locomoção exploratória em direção ao brinquedo (carro, bola, urso, palhaço, peças do palhaço, radinho, cachorro, sanduíche de borracha, boneca, chocalho, telefone), através dos comportamentos de rastejar, engatinhar, caminhar segurando-se nos móveis e de caminhar livremente, em cada sessão de psicoterapia.

De acordo com a teoria do processo de separaçãoindividuação (Mahler \& cols., 1975/2002), estes comportamentos de locomoção exploratória caracterizam o período de treinamento, o qual é marcado pelos primeiros passos independentes da criança em posição vertical. A criança concentra-se no exercício e domínio de suas próprias habilidades e capacidades autônomas, independentemente do outro ou da mãe. Em termos do desenvolvimento emocional, $\mathrm{o}$ ato de andar proporciona à criança um aumento de sua descoberta da realidade e do ato de testá-la sob seu próprio controle e domínio. Além disso, o andar possui um grande significado, tanto para a mãe como para a criança, pois a criança que começa a andar com a aquisição da locomoção independente em posição vertical, mostra a competência para entrar no mundo dos seres humanos independentes. Sendo assim, o bebê está desenvolvendo a sua autonomia intrapsíquica, a qual pode ser observada através dos comportamentos de locomoção exploratória em direção ao ambiente e ao brinquedo, ao ser capaz de distanciar-se da mãe, a fim de alcançar os brinquedos e os objetos alvo. O desenvolvimento da capacidade de o bebê distanciar-se da mãe com a locomoção, a fim de alcançar os brinquedos e os objetos alvo, denota a sobreposição do período de treinamento inicial com o de diferenciação, através das manifestações comportamentais de desabrochamento, como o direcionamento de objetivos e persistência.

O presente estudo revelou aspectos do desenvolvimento emocional do bebê que não foram vislumbrados pelos estudos empíricos encontrados na literatura sobre o comportamento exploratório do bebê, no contexto da depressão materna, no primeiro ano de vida do bebê. Os estudos tendem a enfatizar as dificuldades dos bebês de mães com indicadores de depressão, sugerindo que estes levam mais tempo para começar a olhar o brinquedo, sorriem menos, tentam alcançar menos, tocam menos e evitam mais o brinquedo, apresentando um menor envolvimento nas tarefas de exploração do brinquedo, necessitando de mais tempo para iniciar os comportamentos de exploração, tais como se aproximar e manipular o brinquedo (Field \& cols., 1996), e concentram-se menos durante a exploração dos brinquedos (Hart \& cols., 1998). Neste estudo, foi possível observar a presença de comportamentos de manipulação e de locomoção exploratória nos bebês de mães com indicadores de depressão. Considerando o comportamento exploratório do bebê como um indicador de autonomia, em que o ambiente exerce importante influência, cabe mencionar a possibilidade de as mães do presente estudo estarem apresentando uma boa interação com os seus bebês, conforme mostrou o estudo de Field, Diego, HernandezReif, Schanberg e Kuhn (2003).

Com relação à depressão materna, cabe lembrar que as mães tinham níveis de depressão leve e moderado. Isto poderia nos levar a pensar que por este motivo os bebês apresentaram um nível de desenvolvimento cognitivo, motor e sócio-emocional esperado para a sua faixa etária. No entanto, não foram encontrados estudos que comparassem o impacto de diferentes níveis de depressão materna no desenvolvimento do bebê. Os estudos de Murray (1992), Murray e cols. (1996a), Murray, Kempton, Woolgar e Hooper (1993), entre outros estudos, sobre a depressão materna e o desenvolvimento infantil, consideram apenas a presença ou não de indicadores de depressão, a partir do ponto de corte de 12 pontos na BDI. Outro aspecto a ser discutido sobre o impacto da depressão materna no desenvolvimento do bebê refere-se à presença de rede de apoio às mães. Todas as mães e seus bebês moravam na casa de algum membro da família, como da tia (Caso I), dos pais (Caso II), ou da irmã (Caso III). O fato de as mães contarem com esta matriz de apoio pode também ter auxiliado no desenvolvimento dos bebês, na medida em que podiam contar com outros parceiros de interação.

\section{Comportamentos maternos}

Os resultados apóiam as evidências apresentadas por alguns autores que a mãe, ao interagir com o bebê, relaciona-se não apenas com o comportamento observado de maneira objetiva, mas também com os aspectos subjetivos, como sentimentos e imagens (modelos), os quais pertencem à mãe e aparecem na inte- 
ração com o bebê (Bowlby, 1989; Brazelton \& Cramer, 1992; Hinde, 1992) por meio da identificação projetiva (Brazelton \& Cramer, 1992). Isto pôde ser observado na compreensão dinâmica, realizada em cada sessão de psicoterapia, em que os comportamentos maternos frente aos comportamentos de manipulação e de locomoção exploratória dos bebês foram compreendidos à luz dos sentimentos vivenciados na história de vida das mães com pessoas significativas para elas.

A presença da identificação projetiva pôde ser evidenciada na análise de um outro aspecto objetivo de interação da mãe com o bebê, qual seja, o comportamento direto ou indireto com o bebê. No Caso I, a análise do comportamento da mãe revelou a presença de um padrão caracterizado pelo comportamento indireto frente ao comportamento exploratório do bebê, em que a mãe não olhava diretamente para o bebê ao se referir e ao interagir com o mesmo, mostrando-se distante. Este padrão de comportamento indireto frente ao comportamento exploratório do bebê foi compreendido a partir das características individuais da mãe, a qual caracterizava-se por se distanciar de seus próprios afetos ao falar de si e do bebê nas sessões de psicoterapia, bem como à luz dos sentimentos vivenciados na história de vida da mãe com pessoas significativas. O Caso I relatou a vivência de sentimento de rejeição em relação aos seus pais, assim como o sentimento de não poder contar com a sua mãe, desde quando era muito pequena. Dessa forma, o padrão de comportamento indireto da mãe frente ao comportamento exploratório do bebê poderia estar expressando o sentimento de rejeição e a imagem (modelo) de não poder contar com a figura de apego (mãe), conforme vivenciou no passado. Sendo assim, foi possível observar, na interação da mãe com o bebê, a partir dos comportamentos, a presença de conteúdos da história de vida da mãe, vivenciados no passado.

No Caso II, a análise do comportamento da mãe revelou a presença de um padrão caracterizado pelo comportamento direto frente ao comportamento exploratório do bebê, em que a mãe olhava diretamente para o bebê ao se referir e ao interagir com o mesmo, bem como o apoiava fisicamente, mostrando-se próxima. Este padrão de comportamento direto frente ao comportamento exploratório do bebê foi compreendido à luz dos sentimentos vivenciados na história de vida da mãe com pessoas significativas. O Caso II relatou uma vivência de sentimento de proximidade com a sua mãe, que sempre esteve disponível para ela, suprindo as faltas do pai em casa. Em relação ao pai, o Caso II mencionou uma vivência de sentimento de ausência física e afetiva, o que lhe despertava a impressão de ele não ter afeição por ela. Dessa forma, o padrão de comportamento direto da mãe frente ao comportamento exploratório do bebê poderia estar expressando o sentimento de disponibilidade e a imagem (modelo) de estar sempre presente e próxima com a figura de apego (mãe), conforme vivenciou no passado. Este padrão de comportamento direto da mãe frente ao comportamento exploratório do bebê também poderia estar expressando uma imagem (modelo) de compensação da mãe pela falta do pai do bebê, pois a mãe do Caso II relatou que a sua mãe exercia o papel de mãe e de pai. Sendo assim, foi possível observar, na interação da mãe com o bebê, a partir dos comportamentos, a presença de conteúdos da história de vida da mãe, vivenciados no passado.

No Caso III, a análise do comportamento da mãe revelou a presença de um padrão caracterizado pelo comportamento direto frente ao comportamento exploratório do bebê, em que a mãe olhava diretamente para o bebê ao se referir e ao interagir com o mesmo, mostrando-se próxima. Este padrão de comportamento direto frente ao comportamento exploratório do bebê foi compreendido à luz dos sentimentos vivenciados na história de vida da mãe com pessoas significativas. O Caso III relatou a vivência de ter sido sempre muito apegada à família, assim como o sentimento de ser superprotegida pela sua mãe, sofrendo muito com as situações de separação, em especial a morte de seus pais. Dessa forma, o padrão de comportamento direto da mãe frente ao comportamento exploratório do bebê poderia estar expressando o sentimento de disponibilidade e a imagem (modelo) de estar sempre próxima às figuras de apego (mãe e pai), conforme vivenciou no passado. Sendo assim, foi possível observar, na interação da mãe com o bebê, a partir dos comportamentos, a presença de conteúdos da história de vida da mãe, vivenciados no passado.

Ainda no tocante à identificação projetiva, as mães verbalizaram, em alguns momentos das sessões, como percebiam os bebês em termos de independência ou dependência. Nas verbalizações sobre os bebês para a terapeuta, as mães dos Casos I e II enfatizaram a independência de seus bebês. No Caso III, destacou-se uma idéia de dependência, nem tanto pelas verbalizações da mãe sobre o bebê, mas pelos comportamentos da mãe em relação ao bebê. 
Nos Casos I e II, do presente estudo, as mães percebiam-se como sendo pessoas independentes e percebiam os bebês como independentes. Já no Caso III, a mãe percebia-se como sendo uma pessoa dependente e insegura, percebendo o bebê como sendo dependente, permanecendo fisicamente próxima do mesmo, não demonstrando comportamentos de encorajamento frente ao seu comportamento exploratório até a quinta sessão de psicoterapia. De acordo com a história de vida das mães, no Caso I, a mãe relatou que sempre foi independente, desde os dois anos e meio de vida, quando saiu de casa, indo morar na casa da irmã da senhora que adotou a sua mãe. No Caso II, a mãe contou que sempre foi mais independente do que os seus irmãos em relação aos seus pais. E no Caso III, a mãe relatou que sempre foi dependente, assim como muito apegada e superprotegida, em especial pela mãe.

Outro aspecto a ser discutido, trata-se da depressão. Para Winnicott (1958/2001), há depressões altamente patológicas e depressões que são um caminho para o amadurecimento pessoal, consideradas como a evidência de crescimento e saúde no desenvolvimento emocional, pois indica que a pessoa está sentindo em profundidade. Além disso, Winnicott (1963/1999) entende que diante de novas experiências é necessário que a pessoa faça uma reavaliação interna. Esta reavaliação interna é considerada por Winnicott como a própria depressão. Para este autor, a pessoa que se deprime, ao enfrentar novas experiências, está indicando a possibilidade para a realização de atividades construtivas em direção à maturidade.

No presente estudo, constatou-se a presença de uma reavaliação interna diante da nova condição de mãe, em que as mães mencionaram mudanças em seus estilos de vida, desde o nascimento dos bebês, atribuindo a isso à presença de indicadores de depressão. Também, o nível leve de depressão, encontrado nas mães investigadas, poderia ser entendido como característico da depressão favorecedora ao desenvolvimento emocional.

Ainda no que se refere ao valor da depressão, Winnicott sugere que é a partir de uma reavaliação que a pessoa pode ampliar o conhecimento a respeito de si, passando a olhar para si e para o outro de uma outra maneira, o que estaria indicando amadurecimento. No presente estudo, as mães relataram, ao final da psicoterapia, um sentimento de amadurecimento quando passaram a se perceber como mais organizadas, adaptadas e seguras para cuidar de seus bebês.

\section{CONSIDERAÇÕES FINAIS}

O presente estudo revelou que a observação da interação mãe-bebê envolve tanto os aspectos objetivos, comportamentos observados no nível verbal e não verbal, como os aspectos subjetivos, relacionados à história de vida das mães, por meio da identificação projetiva. Com isso, acredita-se que este estudo tenha contribuído para legitimar a análise da interação mãebebê, a partir de conteúdos objetivos e subjetivos, do presente e do passado da mãe, os quais são observados no nível verbal e não-verbal, a fim de se compreender o comportamento exploratório do bebê e da mãe com indicadores de depressão no contexto da psicoterapia.

\section{REFERÊNCIAS}

Bayley, N. (1993). Bayley Scales of Infant Development [Manual]. San Antonio: Psychological Corporation.

Braier, E. A. (1997). Psicoterapia breve de orientação psicanalíti$c a$. São Paulo: Martins Fontes.

Beck, C. T. (2002). Postpartum depression: a methasynthesis. Qualitative Health Research, 12 (4), 453-472.

Beck, C. T, Reynolds, M. \& Rutowsky, P. (1992). Maternity blues and postpartum depression. Journal of Obstetric, Gynecologic and Neonatal Nursing, 21 (4), 287-293.

Beck, A. \& Steer, R. (1993). Beck Depression Inventory [Manual]. San Antonio: Psychological Corporation.

Bowlby, J. (1989). Uma base segura: aplicações clínicas da teoria do apego. Porto Alegre: Artes Médicas.

Brazelton, T. \& Cramer, B. (1992). As primeiras relações. São Paulo: Martins Fontes. (Original publicado em 1990)

Brown, G. W., Andrews, B., Adler, Z. \& Bridge, L. (1986). Social support, self-steem and depression. Psychological Medicine, $16,813-831$.

Cassidy, J. \& Berlin, L. (1994). The insecure/ambivalent pattern of attachment: theory and research. Child Development, 65, 971-991.

Cooper, P. \& Murray, L. (1997). The impact of psychological treatments of postpartum depression on maternal mood and infant development. Em L. Murray \& P. Cooper (Orgs), Postpartum depression and child development (pp. 201-220). New York: Guilford Press.

Cooper, P., Campbell, E., Day, A., Kennerley, H. \& Bond, A. (1998). Nonpsychotic psychiatric disorder after childbirth: a prospective study of prevalence, incidence, course and nature. British Journal of Psychiatry, 152, 799-806.

Cummings, M. E. \& Davies, P. T. (1994). Maternal depression and child development. Journal of Child Psychology and Psychiatry, 35, 73-112.

Cramer, B. (1997). Psychodynamic perspectives on the treatment of postpartum depression. Em L. Murray \& P. Cooper (Orgs), Postpartum depression and child development (pp.237-261). New York: Guilford Press.

Interação em Psicologia, Curitiba, jul./dez. 2006, (10)2, p. 321-332 
Cramer, B. \& Palacio-Espasa, F. (1993). Técnicas psicoterápicas mãe-bebê. Porto Alegre: Artes Médicas. (Original publicado em 1993)

Deal, L. \& Holt, V. (1998). Young maternal age and depressive symptoms: results from the 1988 National Survey. American Journal of Public Health, 88 (2), 266-269.

Field, T., Healy, B., Goldstein, S. \& Guthertz, M. (1990). Behaviorstate matching and synchrony in mother-infant interactions of non-depressed versus depressed dyads. Developmental Psychology, 26, 7-14.

Field, T., Estroff, D., Yando, R., Del Valle, C., Malphurs, J. \& Hart, S. (1996). Depressed mothers's perceptions of infant vulnerability are related to later development. Child Psychiatry and Human Development, 27 (1), 43-53.

Field, T. (1997a). Depressed mothers and their infants. Em L. Murray \& P. Cooper (Orgs.), Postpartum depression and child development (pp. 221-236). New York: Guilford Press.

Field, T. (1997b). The treatment of depressed mothers and their infants. Em L. Murray \& P. Cooper (Orgs.), Postpartum depression and child development (pp. 221-236). New York: Guilford Press.

Field, T. (2000). Infants of depressed mothers. Em S. Johnson, A. Hayes, T. Field, N. Schneiderman \& P. McCabe (Orgs.), Stress, coping and depression (pp. 3-22). London: Lawrence.

Field, T., Diego, M., Hernandez-Reif, M., Schanberg, S. \& Kuhn, C. (2003). Depressed mothers who are good interaction partners versus who are withdrawn or intrusive. Infant Behavior and Development, 26, 238-252.

GIDEP/NUDIF (2003). Entrevista Diagnóstica. Instituto de Psicologia - UFRGS, Porto Alegre. Instrumento não publicado.

Hart, S., Field, T. \& Del Valle, C. (1998). Depressed mother's interactions with their one year old infants. Infant Behavior and Development, 21 (3), 519-525.

Hart, S., Jones, N., Field, T. \& Lundy, B. (1999). One-year-old infants of intrusive and withdrawn depressed mothers. Child Psychiatry and Human Development, 30 (2), 111-120.

Hinde, R. (1992). Ethological and relationships approaches. Em R. Vasta (Ed.), Six theories of child development (pp. 251-281). UK: Jessica Kingsley Publshers Ltd.

Hock, E. \& DeMeis, D. (1990). Depression in mothers of infants: the role of maternal employment. Developmental Psychology, 26 (2), 285-291.

Klaus, M. H., Kennell, J. H. \& Klaus, P. (2000). Vínculo: construindo as bases para um apego seguro e para a independência. Porto Alegre: Artes Médicas.

Kumar, R. \& Robson, K. (1984). A prospective study of emotional disorder in pregnancy and the first postnatal year. British Journal of Psychiatry, 144, 35-47.

Mahler, M., Pine, F. \& Bergman, A. (2002). O nascimento psicológico da criança. Porto Alegre: Artes Médicas. (Original pu-blicado em 1975)

Murray, L. (1992). The impact of postnatal depression on infant development. Journal of Child Psychology and Psychiatry, 33, 543-561.

Murray, L., Kempton, C., Woolgar, M. \& Hooper, R. (1993). The nature of postpartum depression. Journal of Child Psychology and Psychiatry, 34, 1080-1101.
Murray, L., Fiori-Cowley, A. \& Hooper, R. (1996). The impact of postnatal depression and associated adversity on early motherinfant interactions and later infant outcome. Child Development, 67, 2512-2526.

Murray, L., Hipwell, A. \& Hooper (1996). The cognitive development of 5 year old children of postnatally depressed mothers. Journal of Child Psychiatry, 37 (8), 927-935.

O’Hara, M., Zekoski, E., Phillips, L. \& Wright, E. (1990). Controlled prospective study of postpartum mood disorders: comparison of childbearing and nonchildbearing women. Journal of Abnormal Psychology, 9, 3-15.

Piccinini, C. (2003). Projeto de pesquisa longitudinal "O impacto da psicoterapia para a depressão materna e para a interação pais-bebê: Estudo longitudinal do nascimento ao segundo ano de vida do bebê". Grupo de Interação Social, Desenvolvimento e Psicopatologia - GIDEP.

Prado, L. C. (1996). Pontes entre concepções psicanalíticas e sistêmicas. Em L. C. Prado (Org.), Famílias e terapeutas (p. 68-89). Porto Alegre: Artes Médicas.

Pfost, K., Stevens, M. \& Lunn, C. (1990). The relationship of demografic variables, antepartum depression and stress to postpartum depression. Journal of Clinical Psychology, 46 (5), 588-592.

Reading, R. \& Reynolds, S. (2001). Debt, social disadvantage and maternal depression. Social Science \& Medicine, 53, 441-453.

Romito, P., Saurel-Cubizolles, M. \& Lelong, J. (1999). What makes new mothers unhappy: psychological distress one year after birth in Italy and France. Social Science \& Medicine, 49, 1651-1661.

Schermann, L. \& Alfaya, C. (2000). Depressão pós-parto: tendências atuais. Revista de Medicina da PUCRS, 10 (2), 130-136.

Stake, R. (1994). Case studies. Em N. Denzin \& Y. Lincoln (Orgs.), Handbook of qualitative research (pp. 59-65). London: Sage.

Stern, D. N. (1997). A constelação da maternidade: o panorama da psicoterapia pais/bebê. Porto Alegre: Artes Médicas. (Original publicado em 1995)

Turnbull, A. \& Turnbull, R. (2001). Self-determination for individuals with significant cognitive disabilities and their families. The Journal of Association for Person with Severe Handicaps, 26, 50-62.

Warner, R., Appleby, L., Whitton, A. \& Faragher, B. (1996). Demographic and obstetric risk factors for postnatal psychiatric morbidity. British Jornal of Psychiatry, 168, 607-611.

Whiffen, V. \& Gotlib, I. (1989). Infants of postpartum depressed mothers: temperament and cognitive status. Journal of Abnormal Psychology, 98, 274-279.

Winnicott, D. (1982). Preocupação materna primária. Em D. Winnicott (Org.), Textos selecionados: da pediatria à psicanálise (pp. 26-33). Rio de Janeiro: Francisco Alves. (Original publicado em 1956)

Winnicott, D. (1983). A teoria do relacionamento paterno-filial. Em D. Winnicott (Org.), O ambiente e os processos de maturação (pp. 38-54). Porto Alegre: Artes Médicas. (Original publicado em 1960)

Winnicott, D. (1999). O valor da depressão. Em D. Winnicott, Tudo começa em casa (pp. 59-68). São Paulo: Martins Fontes. (Original publicado em 1963) 
Winnicott, D. (2001). A família afetada pela patologia depressiva

\section{Notas:}

1 Parte desta seção foi escrita pelo grupo de terapeutas pesquisadores do GIDEP (UFRGS).

2 O projeto logitudinal "O impacto da psicoterapia para a depressão materna e para a interação pais-bebê: Estudo longitudinal do nascimento ao segundo ano de vida do bebê" (Piccinini, 2003) do qual o presente estudo faz parte, é desenvolvido pelo GIDEP, PPG (UFRGS).

\section{Sobre os autores:}

Cristiane Alfaya: Psicóloga (PUCRS), Terapeuta de casal e família, Doutora em Psicologia do Desenvolvimento (UFRGS) e Professora do Curso de Psicologia do Centro de Ciências da Saúde da Universidade Federal do Recôncavo da Bahia.

Rita de Cássia Sobreira Lopes: Psicóloga, Doutora pela University College London (Inglaterra) e Professora do Curso de PósGraduação em Psicologia do Desenvolvimento da Universidade Federal do Rio Grande do Sul.

Luís Carlos Prado: Médico Psiquiatra, Terapeuta de casal e família e supervisor clínico do GIDEP (UFRGS).

Endereço para correspondência: c.alfaya@terra.com.br. 